\title{
PT4 Stage Finding
}

National Cancer Institute

\section{Source}

National Cancer Institute. pT4 Stage Finding. NCI Thesaurus. Code C48772.

A pathologic primary tumor TNM stage finding. The definition of PT 4 stage finding depends on the particular type of cancer that it refers to; for example, for breast cancer, PT 4 stage finding is defined as follows: cancer with tumor of any size with direct extension to chest wall or skin, but only as described in pT 4 sub-categories, in accordance with TNM guidelines; for cervical cancer, PT 4 stage finding is defined as follows: cancer invades mucosa of bladder or rectum, and/or extends beyond true pelvis (bullous edema is not sufficient to classify a tumor as T4). (from AJCC 7th Ed.) 